\title{
Incidence, management and outcome of women requiring massive transfusion after childbirth in the Netherlands: secondary analysis of a nationwide cohort study between 2004 and 2006
}

Paul I. Ramler ${ }^{1,2^{*}}$, Thomas van den Akker ${ }^{1}$, Dacia D. C. A. Henriquez ${ }^{1,3}$, Joost J. Zwart ${ }^{4}$ and Jos van Roosmalen ${ }^{1,5}$

\begin{abstract}
Background: Postpartum hemorrhage remains the leading cause of maternal morbidity and mortality worldwide. Few population-based studies have examined the epidemiology of massive transfusion for postpartum hemorrhage. The aim of this study was to determine the incidence, management, and outcomes of women with postpartum hemorrhage who required massive transfusion in the Netherlands between 2004 and 2006.

Methods: Data for all women from a gestational age of 20 weeks onwards who had postpartum hemorrhage requiring eight or more red blood cell concentrates were obtained from a nationwide population-based cohort study including all 98 hospitals with a maternity unit in the Netherlands.

Results: Three hundred twenty-seven women who had postpartum hemorrhage requiring massive transfusion were identified (massive transfusion rate 91 per 100,000 deliveries (95\% confidence interval: 81-101)). The median blood loss was $4500 \mathrm{~mL}$ (interquartile range 3250-6000 mL) and the median number of red blood cell concentrates transfused was 11 units (interquartile range 9-16 units). Among women receiving massive transfusion, the most common cause of hemorrhage was uterine atony. Eighty-three women (25\%) underwent hysterectomy, 227 (69\%) were admitted to an intensive care unit, and three women died (case fatality rate 0,9\%).

Conclusion: The number of women in the Netherlands who had postpartum hemorrhage treated with massive transfusion was relatively high compared to other comparable settings. Evidence-based uniform management guidelines are necessary.
\end{abstract}

Keywords: Postpartum hemorrhage, Blood transfusion, Obstetrics, Maternal mortality, Maternal morbidity

\section{Background}

Around the globe, postpartum hemorrhage (PPH) continues to be a leading cause of both maternal morbidity and mortality $[1,2]$. In the Netherlands, PPH is defined by at least $1000 \mathrm{~mL}$ blood loss within $24 \mathrm{~h}$ of giving birth. There has been an increase in the incidence of $\mathrm{PPH}$ among all births in the Netherlands from $4.1 \%$ in

\footnotetext{
* Correspondence: p.i.ramler@lumc.nl

'Department of Obstetrics, Leiden University Medical Center, Leiden, the Netherlands

${ }^{2}$ Department of Obstetrics and Gynecology, Haaglanden Medical Center, The Hague, the Netherlands

Full list of author information is available at the end of the article
}

2000 to $6.4 \%$ in 2013 [3]. Although case definitions of $\mathrm{PPH}$ vary between countries, this rising incidence of $\mathrm{PPH}$ is also evident in other high-income countries [4-8]. An explanation for the increasing rates of $\mathrm{PPH}$ remains unclear.

In high-income countries, pharmacological, mechanical and surgical methods as well as radiological arterial embolization are available to arrest heavy bleeding. In case of life-threatening PPH, access to and use of sufficient quantities of blood products for transfusion to treat severe anemia and correct clotting disorder are critical $[9,10]$. Clinical benefit of blood transfusion in 
obstetric hemorrhage was demonstrated in a hypothetical experimental study showing a 6.5 -fold increase in risk of maternal death had red blood cell concentrates (RBCs) not been available, as is the case in many lowincome settings [11].

Little is known about the management and outcomes of women who sustain PPH requiring massive transfusion. A recent population-based study from the United Kingdom (UK) indicated that $\mathrm{PPH}$ requiring massive transfusion was associated with high rates of morbidity and hysterectomy [12]. While the rate of obstetric transfusion in the Netherlands has decreased dramatically over time (from $23 \%$ in 2000 to $3.9 \%$ in 2013), transfusion rates in other high-income countries increased [3, 13, 14]. If rates of massive transfusion in the Netherlands were to have decreased over time, these data would be important for informing discussion about best transfusion practices for PPH management. The objective of our present study was to determine incidence, causes, management and clinical outcome of women with PPH requiring massive transfusion in the Netherlands.

\section{Methods}

To determine incidence, causes, management approaches, and clinical outcomes of women who had PPH requiring massive transfusion in the Netherlands, we performed a secondary analysis of data from the LEMMoN study (Landelijke studie naar Etnische determinanten van Maternale Morbiditeit in Nederland) [15].

The LEMMoN study included 358,874 deliveries with severe acute maternal morbidity that occurred in 98 hospitals with a maternity unit in the Netherlands (100\%) between 1st August 2004 and 1st August 2006. Severe acute maternal morbidity was categorized into five groups: intensive care unit (ICU) admission, uterine rupture, eclampsia/HELLP syndrome, major obstetric hemorrhage and a miscellaneous group. Major obstetric hemorrhage was defined as a need for transfusion of four or more units of erythrocyte concentrate or embolization or hysterectomy following PPH. Detailed information about study design and data collection were described previously [15]. For this specific study, we selected women from the LEMMoN cohort who were classified as 'major obstetric hemorrhage', had a gestational age of at least 20 weeks and received massive transfusion, defined as eight or more red blood cell concentrates within the first $24 \mathrm{~h}$ after delivery.

We recorded maternal characteristics (age, body mass index (BMI), geographical ethnic origin (the Netherlands, other European Countries or non-Western immigrants, subdivided into Middle East/North Africa, sub-Saharan Africa, South America and Far East), parity, previous experienced PPH and previous cesarean section), pregnancy characteristics (gestational age, mode of delivery, induction of labour, multiple pregnancy and preeclampsia) and specific data on postpartum hemorrhage (amount of blood loss, number of red blood cell concentrates transfused, hemoglobin levels at onset of bleeding, after bleeding and at day of discharge). Maternal and pregnancy characteristics of women in this study were compared to the general pregnant population of the Netherlands, obtained from Statistics Netherlands (CBS) and National Perinatal Database (LVR-2). Incidence figures in LVR-2 were multiplied by $59 / 100$ to also represent all deliveries under primary care (41\% in 2002) $[16,17]$.

Since postpartum hemorrhage is often the result of concurrent causes, we re-examined all cases of massive transfusion within the LEMMoN-cohort and registered up to three causes of $\mathrm{PPH}$ requiring massive transfusion for each individual case. Only those causes that contributed significantly to the hemorrhage were registered. These causes were noted as uterine atony, uterine rupture, iatrogenic during/after cesarean section, placental abnormalities (including retained placenta, placental remnant, placenta previa, abnormally invasive placenta and placental abruption (resulting in continuous hemorrhage in the postpartum period), laceration of vagina and/or cervix, primary clotting disorder with or without amniotic fluid embolism, rupture of the uterine artery, rupture of the liver capsule and uterine inversion. Causes of hemorrhage were analyzed by mode of birth (spontaneous vaginal delivery, instrumental vaginal delivery, elective cesarean section, emergency cesarean section and termination of pregnancy) and number of red blood cell concentrates transfused ('moderate' (8-12 units), 'high' (13-20 units) and 'immense' ( $>20$ units). The cut-off points for the number of red blood cell concentrates transfused were identical to those described by Green et al. [12].

Management of postpartum hemorrhage requiring massive transfusion was divided into uterotonic agents (oxytocin, prostaglandin F2 $\alpha$, ergometrine, misoprostol), non-uterotonic drugs (tranexamic acid), mechanical interventions (intrauterine balloon, intrauterine packing and intra-abdominal packing), surgical interventions (removal of the placenta not performed during cesarean section, laparotomy, re-laparotomy, B-Lynch suture, uterine artery ligation and hysterectomy) and uterine artery embolization. Outcome of women was determined by need for hysterectomy, length of hospitalization, ICU admission, morbidity, maternal deaths and case fatality rate.

Statistical analyses were performed using IBM SPSS Statistics (version 22.0; SPSS Inc., Chicago, IL). Discrete data were summarized as frequencies and percentages, while continuous data were noted as medians with an interquartile range (IQR) expressed as the 25th and 75th percentiles. Women with a missing value for a specific parameter were excluded when calculating the rate for that variable. 


\section{Results}

During the study period, 358,874 deliveries took place in the Netherlands; 336 women sustained PPH and were given eight or more units of red blood cell concentrates. Of these women, nine were excluded due to a gestational age below 20 weeks, leaving 327 women for analysis. Incidence of massive transfusion due to $\mathrm{PPH}$ was 91 per 100,000 deliveries (95\% confidence interval [95\% CI]: 81101). Clinical and demographic baseline characteristics for women are presented in Table 1 and characteristics of the pregnancies in Table 2. The median (IQR) age, BMI and gestational age were 33 years (30-36 years), $23 \mathrm{~kg} / \mathrm{m}^{2}$ $\left(21-26 \mathrm{~kg} / \mathrm{m}^{2}\right)$ and 38 weeks (37-41 weeks), respectively.

\section{Characteristics of postpartum hemorrhage requiring massive transfusion}

The median (IQR) estimated blood loss was $4500 \mathrm{~mL}$ (3250-6000 mL), resulting in a median (IQR) hemoglobin

Table 1 Characteristics of the women

\begin{tabular}{|c|c|c|c|}
\hline & $\mathrm{N}$ & (\%) & $\begin{array}{l}\text { General pregnant } \\
\text { population in the } \\
\text { Netherlands }(\%)^{\mathrm{a}}\end{array}$ \\
\hline \multicolumn{4}{|l|}{ Age (years) } \\
\hline $20-34$ & 208 & (63) & $(75.3)$ \\
\hline $35-39$ & 94 & (29) & $(21.3)$ \\
\hline$\geq 40$ & 25 & (8) & (3.4) \\
\hline \multicolumn{4}{|l|}{ BMI $\left(\mathrm{kg} / \mathrm{m}^{2}\right)$} \\
\hline$<18,5$ & 15 & (5) & $(3.1)$ \\
\hline $18,5-24,9$ & 137 & (42) & $(65.2)$ \\
\hline $25,0-29,9$ & 39 & (12) & $(21.9)$ \\
\hline$\geq 30$ & 24 & (7) & (9.8) \\
\hline Unknown & 112 & (34) & - \\
\hline \multicolumn{4}{|l|}{ Geographical ethnic origin } \\
\hline The Netherlands & 223 & (68) & N/A \\
\hline Other European Countries & 7 & (2) & N/A \\
\hline Non-Western immigrants; & 70 & (22) & $(16.8)$ \\
\hline Middle East/North Africa & 28 & (7) & N/A \\
\hline Sub-Saharan Africa & 17 & (5) & N/A \\
\hline South America & 16 & (5) & N/A \\
\hline Far East & 9 & (3) & N/A \\
\hline Unknown & 27 & (8) & - \\
\hline \multicolumn{4}{|l|}{ Parity } \\
\hline 0 & 158 & $(48.3)$ & $(45.2)$ \\
\hline $1-2$ & 145 & $(44.3)$ & $(49.8)$ \\
\hline$\geq 3$ & 24 & $(7.3)$ & $(5.0)$ \\
\hline Previous postpartum hemorrhage & 40 & (12) & N/A \\
\hline Previous cesarean section & 66 & (20) & $(6.0)$ \\
\hline
\end{tabular}

N/A data not available

${ }^{a}$ National reference values from Statistics Netherlands (exact study period) [16]
Table 2 Characteristics of pregnancy and birth

\begin{tabular}{|c|c|c|c|}
\hline & $\mathrm{N}$ & (\%) & $\begin{array}{l}\text { General pregnant } \\
\text { population in } \\
\text { the Netherlands (\%) }\end{array}$ \\
\hline \multicolumn{4}{|l|}{ Gestational age } \\
\hline Preterm (<37 weeks); & 86 & (26) & $(5.8)^{\mathrm{b}}$ \\
\hline 20-24 weeks & 6 & (2) & N/A \\
\hline 24-32 weeks & 18 & (5) & N/A \\
\hline 32-37 weeks & 62 & (19) & N/A \\
\hline Full Term & 241 & (74) & $(94.2)^{b}$ \\
\hline \multicolumn{4}{|l|}{ Mode of delivery ${ }^{c}$} \\
\hline Vaginal & 131 & $(40)$ & $(78.4)^{\mathrm{b}}$ \\
\hline Instrumental & 43 & (13) & $(8.6)^{b}$ \\
\hline Cesarean Section; & 151 & (46) & $(13.0)^{b}$ \\
\hline Elective & 46 & (14) & N/A \\
\hline Emergency & 105 & (32) & N/A \\
\hline Induction of labour & 100 & (31) & $(12.5)^{b}$ \\
\hline Multiple pregnancy & 37 & (11) & $(1.7)^{\mathrm{a}}$ \\
\hline Preeclampsia during pregnancy & 54 & (17) & (4) $[19]$ \\
\hline \multicolumn{4}{|c|}{$\begin{array}{l}\text { N/A data not available } \\
\text { a National reference values from Statistics Netherlands (exact study period) [16] } \\
{ }^{\mathrm{b}} \text { National reference values from the Netherlands Perinatal Registry (LVR-2, } \\
\text { 2005) [17] } \\
\text { CIn case of multiple births were the mode of delivery differed between the }\end{array}$} \\
\hline
\end{tabular}

drop from $11.6 \mathrm{~g} / \mathrm{dL}(10.8-12.41 \mathrm{~g} / \mathrm{dL}$; data missing for 60 women) before hemorrhage to $5.96 \mathrm{~g} / \mathrm{dL}(5-6.77 \mathrm{~g} / \mathrm{dL}$; data missing for 34 women) after hemorrhage. The median (IQR, range) number of red blood cell concentrates transfused was $11(9-16,8-52)$ (see Additional file 1 for distribution).

The most common cause of PPH requiring massive transfusion was uterine atony, followed by retained placenta and placenta previa (Table 3). For 117 women $(36 \%)$, two causes were registered and for 12 women (4\%) three. The commonest combinations for women with two causes were uterine atony with retained placenta $(N=28)$, uterine atony with placental remnant $(N=21)$ and uterine atony with cervical laceration $(N=10)$. For women with three causes, the most frequent combination was uterine atony with placental remnant and cervical laceration $(N=3)$. For nine women, no cause could be established. The 22 causes in the 'other' category in Table 3 were primary clotting disorder without amniotic fluid embolism $(N=7)$, uterine artery rupture $(N=6)$, live capsule rupture $(N=4)$, clotting disorder due to amniotic fluid embolism $(N=4)$ and uterine inversion $(N=1)$. Massive transfusion occurred during normal working hours (between 0800 and 1600 on a weekday) for 196 (65\%) women; data were missing for 25 women. The onset of hemorrhage occurred at home for 52 (16\%) women; data were missing for 7 women. 
Table 3 Causes of PPH cases requiring massive transfusion ${ }^{a}$

\begin{tabular}{lll}
\hline & $\mathrm{N}$ & $(\%)$ \\
\hline Uterine atony & 179 & $(55)$ \\
Placenta abnormalities; & 173 & $(53)$ \\
Retained & 54 & $(17)$ \\
Previa & 37 & $(11)$ \\
Abnormally invasive placenta & 32 & $(10)$ \\
Remnant & 30 & $(9)$ \\
Abruption & 20 & $(6)$ \\
Laceration; & 40 & $(12)$ \\
Vagina & 23 & $(7)$ \\
Cervix & 17 & $(5)$ \\
Uterine rupture & 20 & $(6)$ \\
latrogenic during/after cesarean & 11 & $(3)$ \\
Other & 22 & $(7)$ \\
Unknown & 9 & $(3)$ \\
\hline
\end{tabular}

${ }^{\mathrm{a} U p}$ to three causes per case could be included

Table 4 presents the top three causes of postpartum hemorrhage requiring eight or more units of red blood cells according to mode of birth. The commonest cause during elective cesarean section was placenta previa (52\%, $N=24 / 46)$, whereas uterine atony remained the leading cause for the other modes of delivery. Categorizing causes of PPH by number of red blood cell concentrates transfused, respectively 'moderate' $(N=193)$, 'high

Table 4 Top 3 causes categorized by mode of birth ${ }^{a}$

\begin{tabular}{lll}
\hline & $N$ & $(\%)$ \\
\hline Vaginal birth $(N=131)$ & 84 & $(64)$ \\
1. Uterine atony & 40 & $(31)$ \\
2. Retained placenta & 20 & $(15)$ \\
3. Placental remnant & & \\
Instrumental vaginal birth $(N=43)$ & 26 & $(60)$ \\
1. Uterine atony & 14 & $(33)$ \\
2. Retained placenta & 6 & $(14)$ \\
3. Placental remnant & & \\
Elective cesarean section $(N=46)$ & 24 & $(52)$ \\
1. Placenta previa & 17 & $(37)$ \\
2. Uterine atony & 13 & $(28)$ \\
3. Abnormally invasive placenta & & \\
Emergency cesarean section $(N=105)$ & 51 & $(49)$ \\
1. Uterine atony & 13 & $(12)$ \\
2. Uterine rupture & 9 & $(50)$ \\
3. latrogenic during/after cesarean \\
Termination of pregnancy $(n=2)$ \\
1. Uterine atony \\
2. Uterine rupture
\end{tabular}

ap to three causes could be included
( $N=89)$ and 'immense' $(N=39)$, showed no difference in prevalence of causes; uterine atony continued to be the main cause in each group.

\section{Management of postpartum hemorrhage requiring massive transfusion}

Oxytocin (84\%) was the most frequently administered uterotonic agent (prophylactic oxytocin excluded), followed by prostaglandin F2 $\alpha$ (70\%) and ergometrine (18\%) (Table 5). No data regarding which uterotonic agent was administered as first line treatment were retrievable, but of 284 women who received oxytocin, 210 (74\%) were given prostaglandin F2 $\alpha$ thereafter. Eleven women who had uterine atony received no oxytocin. Instead, these women received prostaglandin F2 $\alpha$ and one woman was supplemented with tranexamic acid.

Laparotomy was performed following 42/174 (24\%) vaginal deliveries and 82/151 (54\%) cesarean sections. Relaparotomy was necessary in 10/42 (24\%) and 20/82 (24\%) respectively. Of all 327 women, 83 (25\%) underwent hysterectomy to control bleeding with highest rates in women who sustained uterine rupture $(N=14 / 20,70 \%)$ or any form of abnormal placentation $(N=21 / 32,66 \%)$.

\section{Outcome of women requiring massive transfusion}

The median (IQR) length of hospitalization was 9 days (613 days; data missing for 14 women) and 227 women (69\%) required ICU admission. The median (IQR) hemoglobin on the day of discharge was $10.15 \mathrm{~g} / \mathrm{dL}(9.02-11.44 \mathrm{~g} / \mathrm{dL}$; data missing for 53 women). One-hundred-and-twenty-one (37\%) women experienced some kind of morbidity, of whom 40 (33\%) developed respiratory failure and 13 (11\%) experienced renal insufficiency. Other complications were paralytic ileus $(N=11)$, heart failure $(N=7)$, Sheehan syndrome $(N=6)$ and cerebral venous sinus thrombosis $(N=2)$. Maternal death occurred in three women due to hypovolemic shock, ventricular fibrillation and massive pulmonary embolism; case fatality rate of postpartum hemorrhage requiring massive transfusion was 1 in $109(0,9 \%)$.

\section{Discussion}

Between 2004 and 2006, the incidence of postpartum hemorrhage treated with massive transfusion was notably high in the Netherlands (91 per 100,000 deliveries). This is four times the incidence reported for the United Kingdom between 2012 and 2013 (23 per 100,000 deliveries), and one-and-a-half times the incidence reported for the state of New York between 1998 and 2007 (60 per 100,000 deliveries) [12, 18]. We found that the leading cause of $\mathrm{PPH}$ with massive transfusion was uterine atony. One quarter of all women receiving massive transfusion underwent hysterectomy to control bleeding. 
Table 5 Distribution of obstetric interventions by cause; expressed as percentages

\begin{tabular}{|c|c|c|c|c|c|c|c|}
\hline & $\begin{array}{l}\text { Atony } \\
(N=179)\end{array}$ & $\begin{array}{l}\text { Rupture } \\
(N=20)\end{array}$ & $\begin{array}{l}\text { Previa } \\
(N=37)\end{array}$ & $\begin{array}{l}\text { AlP }^{a} \\
(N=32)\end{array}$ & $\begin{array}{l}\text { Abruption } \\
(N=20)\end{array}$ & $\begin{array}{l}\text { Retained } \\
(N=54)\end{array}$ & $\begin{array}{l}\text { Total } \\
(N=327)\end{array}$ \\
\hline Oxytocin & 94 & 70 & 87 & 91 & 70 & 87 & 84 \\
\hline Prostaglandin F2a & 87 & 50 & 54 & 72 & 55 & 85 & 70 \\
\hline Tranexamic acid & 33 & 5 & 19 & 13 & 5 & 19 & 22 \\
\hline Ergometrine & 23 & 15 & 14 & 19 & 20 & 28 & 18 \\
\hline Misoprostol & 16 & 5 & 3 & 3 & 20 & 6 & 11 \\
\hline Removal of placenta ${ }^{b}$ & 31 & 15 & 11 & 41 & 15 & 100 & 29 \\
\hline Intrauterine balloon & 32 & 10 & 14 & 28 & 5 & 19 & 23 \\
\hline Intrauterine packing & 30 & 15 & 22 & 22 & 5 & 22 & 21 \\
\hline Intra-abdominal packing & 6 & 30 & 0 & 3 & 0 & 4 & 7 \\
\hline Uterine artery ligation & 6 & 5 & 8 & 3 & 5 & 4 & 5 \\
\hline Uterine artery embolization & 29 & 10 & 19 & 19 & 5 & 22 & 22 \\
\hline Laparotomy & 36 & 70 & 51 & 63 & 15 & 13 & 38 \\
\hline Re-laparotomy & 8 & 30 & 5 & 0 & 0 & 6 & 9 \\
\hline B-Lynch suture & 5 & 0 & 3 & 3 & 10 & 0 & 2 \\
\hline Hysterectomy & 27 & 70 & 38 & 66 & 5 & 9 & 25 \\
\hline
\end{tabular}

${ }^{a}$ Abnormally invasive placenta

${ }^{b}$ Included only removal of the placenta (or placental remnant) not performed during cesarean section

The difference in the incidence of massive transfusion due to $\mathrm{PPH}$ between the Netherlands and the UK is remarkable. Whereas incidence of major obstetric hemorrhage has differed between various countries as a result of varying inclusion criteria $[15,19,20]$, our study applied the same inclusion criteria for massive transfusion described by Green et al. [12] The difference in incidence between the Netherlands and the state of New York is also of note, particularly since Mhyre et al. [18] used a higher threshold for the number of red blood cell concentrates transfused to define massive transfusion ( $\geq 10$ units) and included both antepartum and postpartum hemorrhage.

A distinct difference between the national guidelines for the management of PPH between the Netherlands (Dutch Society of Obstetrics and Gynaecology (NVOG)) and the United Kingdom (Royal College of Obstetricians and Gynaecology (RCOG)) is that the RCOG specifically recommends that 'surgical interventions should be initiated sooner rather than later'. Both guidelines are inconclusive concerning the administration of blood products; NVOG (see Additional file 2 for a summary of the NVOG PPH guideline represented as a chart [9]) recommends not to deviate from the local guidelines of the hospital, while RCOG states that the decision to provide blood transfusion 'should be based on both clinical and hematological assessment' $[9,10,21]$. Furthermore, it is noteworthy that the median estimated blood loss in the study from Green et al. was $6 \mathrm{~L}(4.5-8.0 \mathrm{~L})$ versus $4.5 \mathrm{~L}$ (3.3-6 L) in our cohort, whilst the massive transfusion rate was four times higher in the Netherlands [12]. This may suggest that the difference in transfusion rate is due to differences in transfusion policy, which would emphasize the need for uniform guidelines [22].

During the study period, there were 358,874 deliveries in the Netherlands and 145,703 deliveries (40.6\%) were under the responsibility of a primary care giver, making the risk of massive transfusion due to $\mathrm{PPH} 13$ per 100.000 deliveries in midwifery care. Comparison of women requiring massive transfusion due to $\mathrm{PPH}$ with the general pregnant population in the Netherlands showed that women requiring massive transfusion had a multiple pregnancy in $11 \%$ of all cases versus $1.7 \%$ in the general population [16], suffered from preeclampsia in $17 \%$ of all cases versus $4 \%$ in the general population [23], had labour induced in $31 \%$ of all cases versus $12.5 \%$ in the general population [17], had a preterm delivery in $26 \%$ of all cases versus $5.8 \%$ in the general population [17] and delivered by cesarean section in $46 \%$ in all cases versus $13 \%$ in the general population [17]. These characteristics are known risk factors of PPH and highlight that the management of postpartum hemorrhage should not only be focused on treatment, but on prevention as well $[24,25]$.

Uterine atony was the most frequent cause of postpartum hemorrhage as is consistent with the literature $[12,26,27]$. Atony was also the commonest cause of $\mathrm{PPH}$ in home deliveries [28]. In elective cesarean sections the leading cause of massive transfusion due to PPH was placenta previa. Green et al. reported placenta accreta as the most frequent cause of $\mathrm{PPH}$ in women delivering by elective cesarean section, while Dupont et al. 
in France found that uterine atony remained the main cause of PPH regardless of mode of birth [12, 27]. The higher percentage of laparotomies performed after cesarean section is consistent with previous findings from the LEMMoN-cohort that the risk of postpartum laparotomy was more than 16 times higher in women who delivered by cesarean section compared to those who delivered vaginally [29].

As a last resort to arrest heavy bleeding, a quarter of all women underwent hysterectomy. This percentage is considerably lower than reported by Green et al. for the UK, where the overall rate of hysterectomy was $45 \%$. A possible explanation for this difference could be the lower rates of previous cesarean deliveries; 66/327 (20\%) in our study versus $73 / 181$ (40\%) in the [12]. Two studies showed that the risk of peripartum hysterectomy increased with the number of previous cesarean deliveries [30,31]. Another contributing factor could be the higher rate of embolization in our study, 72/327 (22\%) versus $29 / 181$ (16\%) in the UK, and thereby preventing the need for hysterectomy. Furthermore, uterine rupture or an abnormally invasive placenta had the highest rates of hysterectomy compared to other causes. This is coherent with the recommendation of the Dutch Society of Obstetrics and Gynaecology guideline that states that hysterectomy should not be postponed if the cause of hemorrhage is related to a placenta accreta or ruptured uterus [10].

The maternal mortality rate of massive transfusion due to PPH in our study was low with 0.84 deaths per 100.000 maternities. This is comparable with the maternal mortality rate of PPH in the Netherlands reported by Schutte et al. between 1993 and 2005 (0.7 deaths per 100.000 maternities) [32]. Nearly three-quarters of women who received massive transfusion were admitted to an ICU, and about one-third experienced morbidity. This high rate of morbidity is consistent with other studies $[12,26]$. The rate of morbidity may be higher in low-income settings where not all treatment modalities are available or for Jehovah's witnesses who refuse blood products $[3,15,33]$.

A key strength is that our results were based on a nationwide cohort compromising all hospitals in the Netherlands with a maternity unit. Considering that $\mathrm{PPH}$ cases requiring massive transfusion must have been managed in one of these units, our results are population-based. Furthermore, our results are directly comparable to those of Green et al. who used the same definition for massive transfusion in their analysis of a UK cohort [12].

However, number of red blood cell concentrates as definition for massive transfusion remains an indicator with shortcomings as well, since it can be influenced by other factors, such as obstetrician's decision-making. We also acknowledge that our data are from 2004 to 2006 and may not reflect the current situation. Since the incidence of $\mathrm{PPH}$ increased significantly throughout the years in many countries, but the incidence of obstetric blood transfusion in the Netherlands decreased [3], it is possible that the incidence of massive transfusion due to $\mathrm{PPH}$ may have reduced in recent years, but this is subject of further assessment. There may have been inclusion bias, since identification and management of cases may differ between obstetricians and hospitals. Underreporting is a concern, however, we have previously observed that there is a negative correlation between the rate of underreporting and the number of red blood cell concentrates transfused [34]. Therefore, we would expect a low rate of underreporting. The considerable number of women without a known Hb-level at discharge is likely due to missing data, as a result of the design of the LEMMoN-database that did not specifically include Hb-level at discharge.

Nevertheless, this study makes clear that the incidence of $\mathrm{PPH}$ requiring massive transfusion was high in the Netherlands at that time compared to other countries and further research of contemporary obstetric cohorts is needed to allow for more up to date international comparisons of rates of transfusion and hemorrhagerelated morbidity. Networks such as the International Network of Obstetric Surveillance Systems (INOSS) could facilitate such studies [35].

\section{Conclusions}

This study adds to the understanding of causes, management and outcomes of women with postpartum hemorrhage requiring massive transfusion and our results show that massive transfusion due to $\mathrm{PPH}$ is complicated by high rates of morbidity and a considerable risk of hysterectomy. The incidence of massive transfusion due to $\mathrm{PPH}$ appears higher in the Netherlands compared to the UK and the US. Increased vigilance for women at risk or in early stages of postpartum hemorrhage in the Netherlands is needed, while avoiding unnecessary over-transfusion. Specific reasons for the higher incidence will have to be studied in order to improve care accordingly. Our results show the importance of population-wide studies of severe maternal outcome in general, and those comparing rates of transfusion and outcomes for women with severe postpartum hemorrhage in particular.

\section{Additional files}

Additional file 1: Distribution of the number of red blood cells concentrates transfused (PDF $142 \mathrm{~kb}$ ).

Additional file 2: Summary chart of the Dutch Society of Obstetricians and Gynecology PPH guideline [9] (PDF 85 kb). 


\section{Abbreviations}

BMl: Body mass index; CBS: Statistics Netherlands; ICU: Intensive care unit: IQR: Interquartile range; LEMMoN: Landelijke studie naar Etnische determinanten van Maternale Morbiditeit in Nederland; LVR-2: National perinatal database; N/A: Data not available; NVOG: Dutch Society of Obstetrics and Gynaecology; PPH: Postpartum hemorrhage; RBCs: Red blood cell concentrates; RCOG: Royal College of Obstetricians and Gynaecology; UK: United Kingdom

\section{Acknowledgements}

We would like to thank all the 98 local hospital coordinators for participating in the LEMMON study.

\section{Funding}

No funding was received for this study.

\section{Availability of data and materials}

The datasets generated and/or analysed during the current study are not publicly available, since these are owned by Leiden University Medical Centre (LUMC). Subsets are available from the corresponding author on request.

\section{Authors' contributions}

PR and JVR designed the study. PR carried out the analysis and wrote the first draft. JvR, TvdA, JZ, DH all contributed significantly to data analysis, interpretation, and writing of the manuscript. All authors have read and approved the final version of this manuscript.

\section{Competing interests}

JvR and TVdA are part of the editorial board of the journal: JvR as a section editor and TvdA as an associate editor.

\section{Consent for publication}

Not applicable.

\section{Ethics approval and consent to participate}

The LEMMoN study was approved by the Medical Ethics Committee of Leiden University Medical Centre (P04-020; March 8, 2004). The ethical approval covers the current study as well.

\section{Publisher's Note}

Springer Nature remains neutral with regard to jurisdictional claims in published maps and institutional affiliations.

\section{Author details}

Department of Obstetrics, Leiden University Medical Center, Leiden, the Netherlands. ${ }^{2}$ Department of Obstetrics and Gynecology, Haaglanden Medical Center, The Hague, the Netherlands. ${ }^{3}$ Department of Obstetrics and Gynecology, Haga Hospital, The Hague, the Netherlands. ${ }^{4}$ Department of Obstetrics and Gynecology, Deventer Hospital, Deventer, the Netherlands. ${ }^{5}$ Athena Institute, VU University, Amsterdam, the Netherlands.

Received: 1 March 2017 Accepted: 13 June 2017 Published online: 19 June 2017

\section{References}

1. Say L, Chou D, Gemmill A, et al. Global causes of maternal deaths: a WHO systematic analysis. Lancet Glob Health. 2014;2:e323-33.

2. Khan KS, Wojdyla D, Say L, Gülmezoglu AM, Van Look PF. WHO analysis of causes of maternal death: a systematic review. Lancet. 2006;267:1066-74.

3. van Stralen G, von Schmidt auf Altenstadt JF, Bloemenkamp KW, van Roosmalen J, Hukkelhoven CWPM. Increasing incidence of postpartum hemorrhage: the Dutch piece of the puzzle. Acta Obstet Gynecol Scand 2016:95:1104-1110.

4. Ford JB, Roberts CL, Simpson JM, Vaughan J, Cameron CA. Increased postpartum hemorrhage rates in Australia. Int J Gynecol Obstet. 2007: 98:237-43.

5. Cameron CA, Roberts CL, Olive EC, Ford JB, Fischer WE. Trends in postpartum haemorrhage. Aust N Z J Public Health. 2006;30:151-6.

6. Callaghan WM, Kuklina EV, Berg CJ. Trends in postpartum hemorrhage: United States, 1994-2006. Am J Obstet Gynecol. 2010;202:353.e1-6.
7. Joseph KS. Rouleau J, Kramer MS, Young DC, Liston RM, Basket TF; For the Maternal Health Study Group of the Canadian Perinatal Surveillance System. Investigation of an increase in postpartum hemorrhage in Canada. BJOG. 2007;114:751-9.

8. Knight M, Callaghan WM, Berg C, et al. Trends in postpartum hemorrhage in high resource countries: a review and recommendations from the International Postpartum Hemorrhage Collaborative Group. BMC Pregnancy Childbirth. 2009:9:55

9. Nederlandse Vereniging voor Obstetrie en Gynaecologie. Haemorrhagia postpartum (versie 2.0). Utrecht: NVOG; 2006. http://www.nvogdocumenten.nl/richtlijn/doc/download.php?id=528. Accessed 12 Dec 2016.

10. Nederlandse Vereniging voor Obstetrie Gynaecologie. NVOG-richtlijn Haemorrhagia postpartum (HPP). Arnhem: NVOG; 2013. http://nvogdocumenten.nl/uploaded/docs/NVOG\%20richtlijn\%20HPP\%2014-112013\%20herzien\%202015lhe.pdf. Accesses 12 Dec 2016.

11. Hendriks J, Zwart JJ, Briet E, Brand A, van Roosmalen J. The clinical benefit of blood transfusion: a hypothetical experiment based on a nationwide survey of severe maternal morbidity. Vox Sang. 2013;104:234-9.

12. Green $L$, Knight M, Seeney FM, et al. The epidemiology and outcomes of women with postpartum haemorrhage requiring massive transfusion with eight or more units of red cells: a national cross-sectional study. BJOG. 2015. DOI: 10.1111/1471-0528.13831.

13. Patterson JA, Roberts $\mathrm{CL}$, Bowen JR, et al. Blood transfusion during pregnancy, birth, and the postnatal period. Obstet Gynecol. 2014;123(1):126-33.

14. Callaghan WM, Kuklina EV, Berg CJ. Trends in postpartum hemorrhage: United States, 1994-2006. Am J Obstet Gynecol. 2010;202(4):353.e1-6.

15. Zwart JJ, Richters JM, Ory F, de Vries JI, Bloemenkamp KW, van Roosmalen J. Severe maternal morbidity during pregnancy, delivery and puerperium in the Netherlands: a nationwide population-based study of 371,000 pregnancies. BJOG. 2008;115:842-50.

16. Statistics Netherlands (CBS). Statline, Central Bureau of Statistics. http://www. cbs.nl/en-GB. (2007). Accessed on 2 Oct 2007.

17. The Netherlands Perinatal Registry. Perinatal Care in The Netherlands. Bilthoven, the Netherlands: the Netherlands Perinatal Registry. 2005:2007.

18. Mhyre JM, Shilkrut A, Kuklina EV, et al. Massive blood transfusion during hospitalization for delivery in New York State, 1998-2007. Obstet Gynecol. 2013;122(6):1288-94

19. Marr L, Lennox C, MCFadyen AK. Quantifying severe maternal morbidity in Scotland: a continuous audit since 2003. Curr Opin Anesthesiol. 2014 27:275-81.

20. Waterstone M, Bewley S, Wolfe C. Incidence and predictors of severe obstetric morbidity: case-control study. BMJ. 2001;322:1089-93.

21. Mayrides E, Allard S, Chandraharan E, et al. Prevention and management of postpartum haemorrhage: green-top guideline no. 52. BJOG. 2017;124(5): e106-49.

22. Shaylor R, Weiniger CF, Austin N, et al. National and international guidelines for patient blood management in obstetrics: a qualitative review. Anesth Analg. 2017;124(1):216-32.

23. Mol BW, Roberts CT, Thangaratinam S, Magee LA, De Groot CJ, Hofmeyer GJ. Pre-eclampsia. Lancet. 2016;287(10022):999-1011.

24. Oyelese Y, Ananth CV. Postpartum hemorrhage: epidemiology, risk factors, and causes. Clin Obstet Gynecol. 2010;53(1):147-56.

25. Bonnet MP, Basso O, Bouvier-Colle $\mathrm{MH}$, et al. Postpartum haemorrhage in Canada and France: a population-based comparison. PLoS One. 2013; 8(6):e66882

26. Bateman BT, Berman MF, Riley LE, Leffert LR. The epidemiology of postpartum hemorrhage in a large, nationwide sample of deliveries. Anesth Analg. 2010;100:1368-73.

27. Dupont C, Rudigoz RC, Cortet M, et al. Frequency, causes and risk factors of postpartum haemorrhage: a population-based study in 106 French maternity units. J Gynecol Obstet Biol Reprod (Paris). 2014;43(3):244-53.

28. Smit M, Chan KL, Middeldorp JM, van Roosmalen J. Postpartum haemorrhage in midwifery care in the Netherlands: validation of quality indicators for midwifery guidelines. BMC Pregnancy Childbirth. 2014;14:397.

29. Witteveen T, Kallianidis A, van den Akker T, Zwart J, Bloemenkamp K, van Roosmalen J. Laparotomy after childbirth: a two-year nationwide cohort study in the Netherlands. Findings have been presented at the $21^{\text {st }} \mathrm{FIGO}$ World Congress of Gynaecology and Obstetrics (4-9 October 2015). Submitted for publication.

30. Knight M, Kurinczuk JJ, Spark P, Brocklehurst P. Cesarean delivery and peripartum hysterectomy. Obstet Gynecol. 2008;111:97-105. 
31. Bateman BT, Mhyre JM, Callaghan WM, Kuklina EV. Peripartum hysterectomy in the United States: nationwide 14 year experience. Am J Obstet Gynecol. 2012;2016(1):63.e1-8

32. Schutte JM, Steegers EAP, Schuitemaker NWE, et al. The Netherlands maternal mortality committee. rise in maternal mortality in the Netherlands. BJOG. 2010;117:399-406.

33. van Wolfswinkel ME, Zwart JJ, Schutte JM, Duvekot JJ, Pel M, van Roosmalen J. Maternal mortality and serious maternal morbidity in Jehovah's witnesses in the Netherlands. BJOG. 2009;116(8):1103-8.

34. Zwart JJ, Yazdani ST, Harvey MS, de Vries RRP, van Roosmalen J. Underreporting of major obstetric haemorrhage in the Netherlands. Transfus Med. 2010;20(2):118-22.

35. Knight M. The International Network of Obstetric Survey Systems (INOSS): benefits of multi-country studies of severe and uncommon maternal morbidities. Acta Obstet Gynecol Scand. 2014;93(2):127-31.

Submit your next manuscript to BioMed Central and we will help you at every step:

- We accept pre-submission inquiries

- Our selector tool helps you to find the most relevant journal

- We provide round the clock customer support

- Convenient online submission

- Thorough peer review

- Inclusion in PubMed and all major indexing services

- Maximum visibility for your research

Submit your manuscript at www.biomedcentral.com/submit
Biomed Central 